Supplement of Earth Syst. Dynam., 13, 303-319, 2022

https://doi.org/10.5194/esd-13-303-2022-supplement

(C) Author(s) 2022. CC BY 4.0 License.

(c) (i)

Supplement of

\title{
Climate change signal in the ocean circulation of the Tyrrhenian Sea
}

\author{
Alba de la Vara et al. \\ Correspondence to: Alba de la Vara (adelavaraf@gmail.com)
}

The copyright of individual parts of the supplement might differ from the article licence. 
Supplementary Material

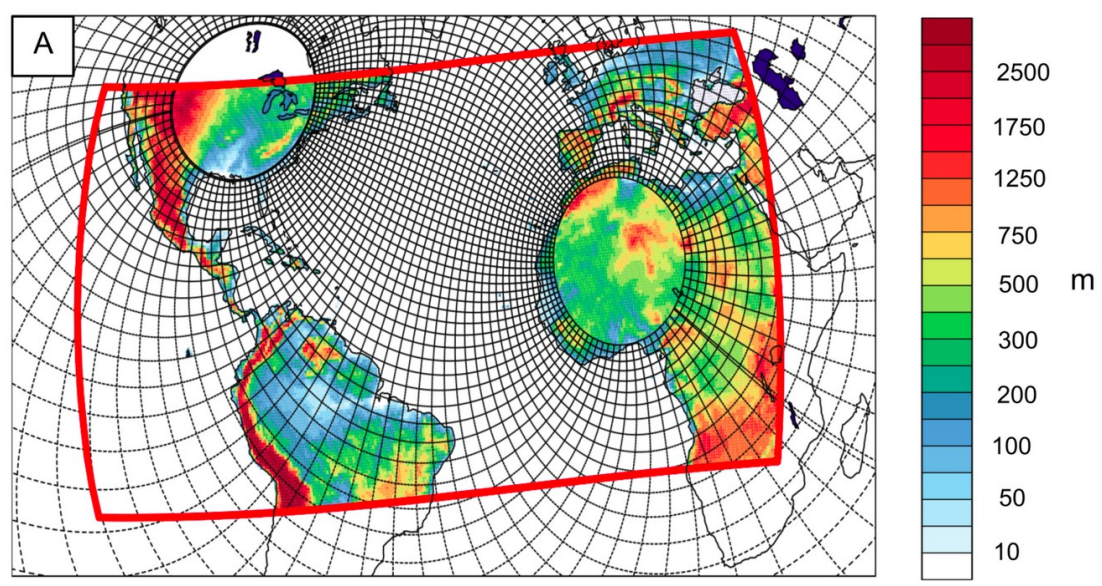

Figure S1: ROM atmospheric and oceanic grids. The red line shows the limits of the atmospheric domain, while the black lines represent the oceanic mesh (each $12^{\text {th }}$ line is shown). This figure is taken from Cabos et al. (2020). 


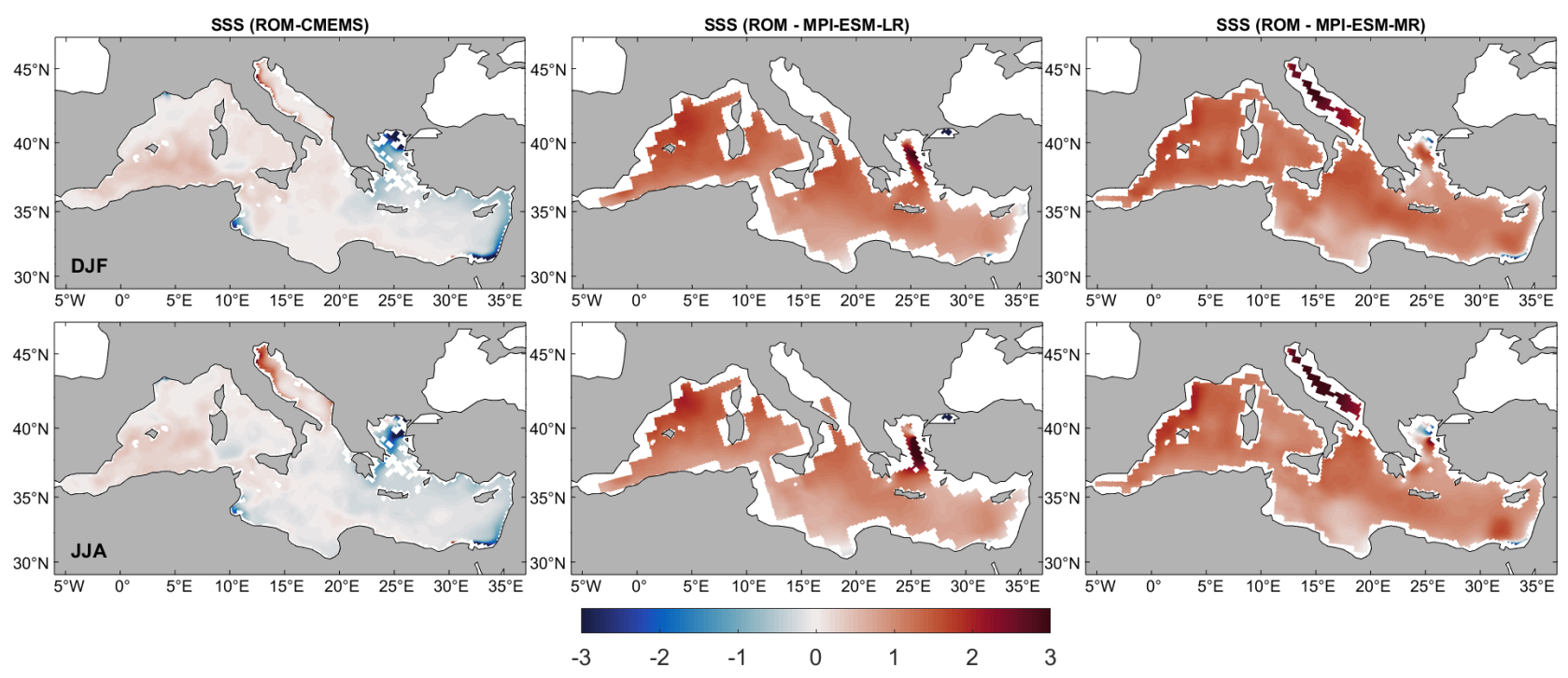

Figure S2: Winter (first row) and summer (second row) differences of Mediterranean sea-surface salinity (SSS; psu) between ROM and a CMEMS reanalysis (first column), MPI-ESM-LR (second column) and MPI-ESMMR (third column), respectively. Differences are computed for the present-time period (1993-2005). Positive values indicate that ROM simulates a greater salinity than the corresponding product and negative values the opposite.

We note that regardless of the season the SSS biases from ROM are smaller with the high-resolution reanalysis from CMEMS*, being the magnitude of the biases much smaller than $0.5 \mathrm{psu}$, with prevailingly negative values in the Eastern Mediterranean. Regarding MPI-ESM, ROM presents positive differences of a magnitude close to 1 psu all over the Mediterraean basin. This fact reflects a negative bias in MPI-ESM with respect to CMEMS, which is partly corrected in our downscaling. 


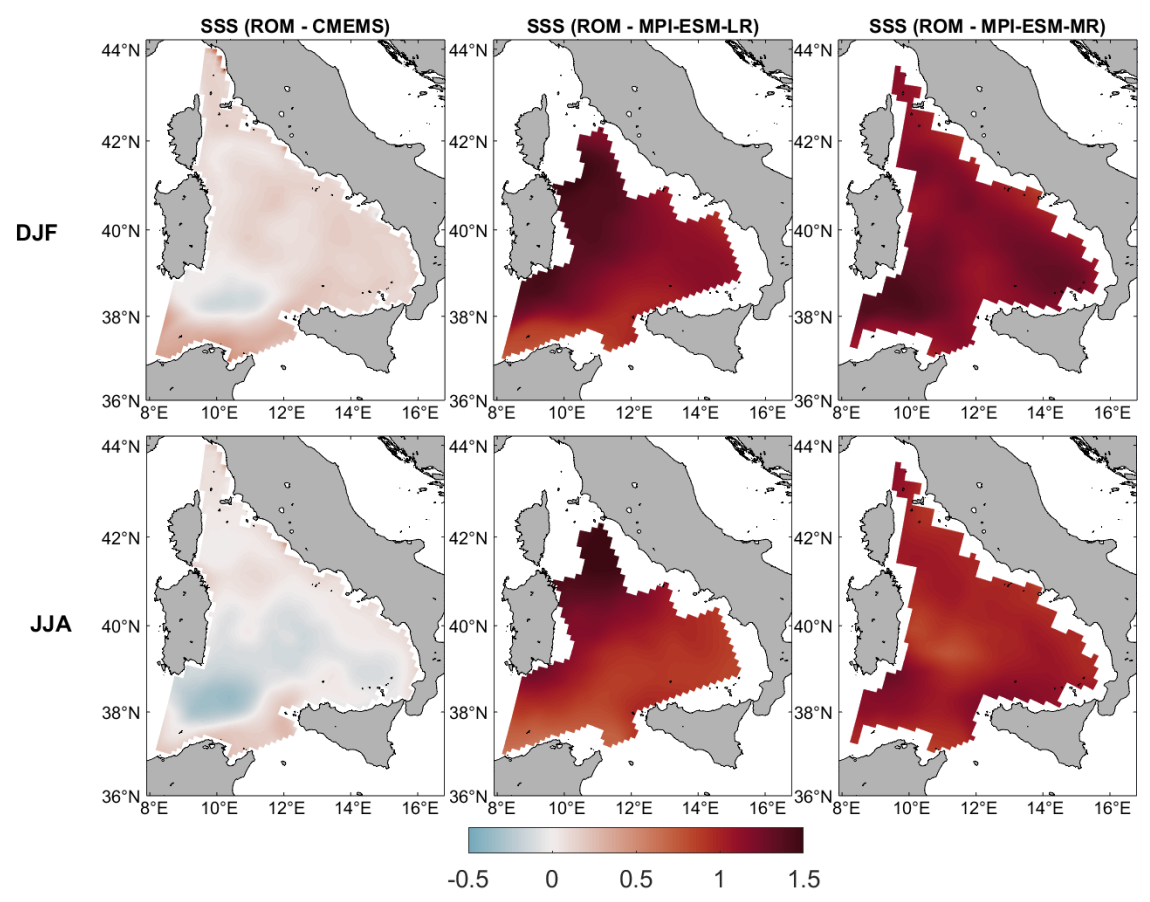

Figure S3: Winter (first row) and summer (second row) differences of Tyrrhenian sea-surface salinity (SSS; psu) between ROM and a CMEMS reanalysis (first column), MPI-ESM-LR (second column) and MPI-ESM-MR (third column), respectively. Differences are computed for the present-time period (1993-2005). Positive values indicate that ROM simulates a greater salinity than the corresponding product and negative values the opposite.

In the Tyrrhenian Sea, as for the Mediterranean Sea, in both seasons the SSS biases from ROM are smaller with the high-resolution reanalysis from CMEMS, being the magnitude of the biases smaller than 0.5 psu, with prevailingly negative values to the south of the basin. With MPI-ESM, ROM presents positive biases of a magnitude close to 1 psu. Again, as for the whole Mediterranean basin, MPI-ESM shows a negative bias with respect to CMEMS, which is partly corrected in our downscaling. 

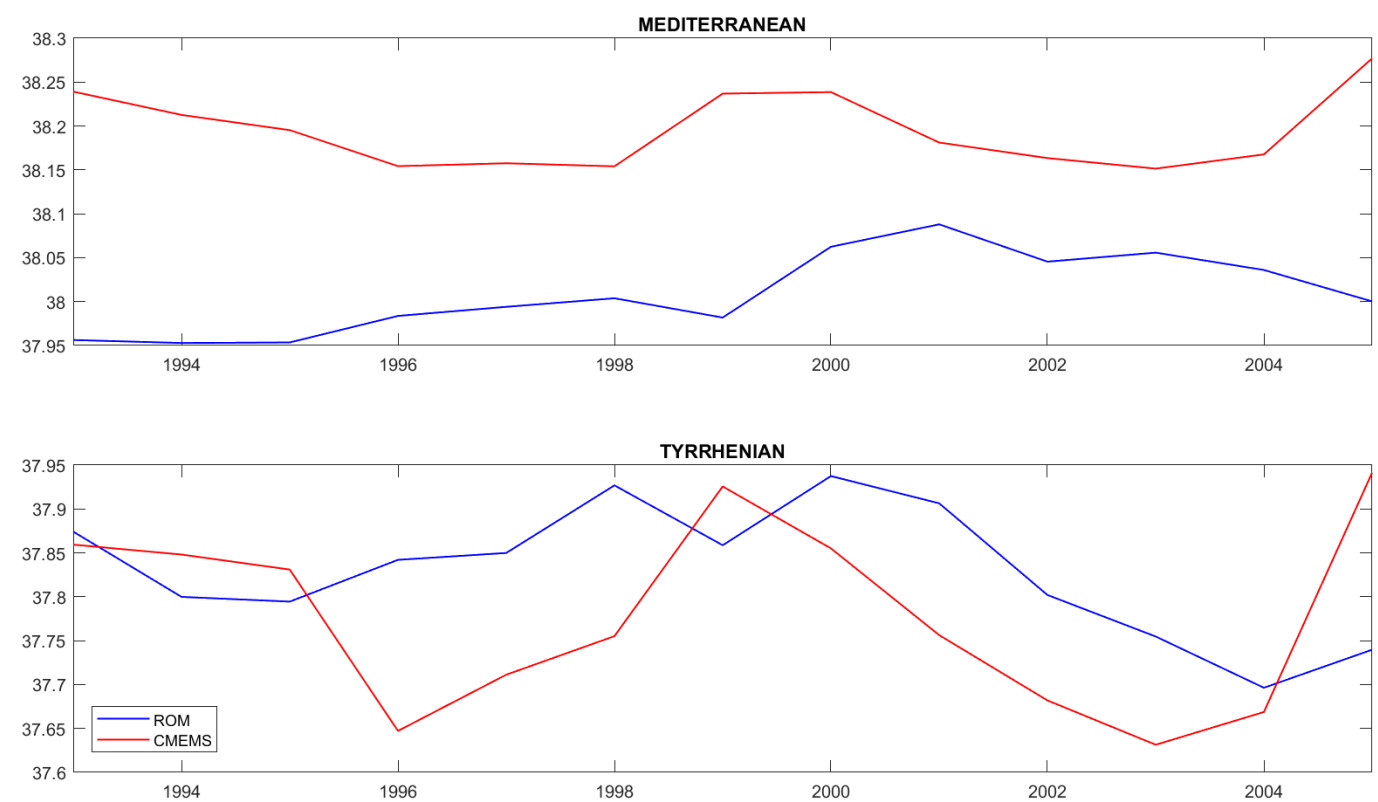

Figure S4: Annual time series of sea-surface salinity (SSS), in psu, for the Mediterranean Sea (upper panel) and the Tyrrhenian Sea (lower panel). The blue lines highlight the results obtained with ROM and the red lines those for CMEMS.

Here we observe that in the Mediterranean, the SSS is lower with ROM than with a CMEMS reanalysis. However, the interannual variability is relatively well represented, although with a small lag (upper panel). In the Tyrrhenian Sea, contrary to what happens in the Mediterranean, the SSS from ROM is generally slightly higher than that from the CMEMS reanalysis, and again the interannual variability is captured. 


\section{References:}

Cabos, W., de la Vara, A., Álvarez-García, F.J. et al.: Impact of ocean-atmosphere coupling on regional climate: the Iberian Peninsula case, Clim. Dyn., 54, 4441-4467, doi:10.1007/s00382-020-05238-x, 2020. 